Published in final edited form as:

Curr Opin Rheumatol. 2018 May ; 30(3): 231-237. doi:10.1097/BOR.000000000000496.

\title{
Recent Advances in the Treatment of Rheumatoid Arthritis
}

Tina D. Mahajan, M.D. ${ }^{1}$ and Ted R. Mikuls, M.D., M.S.P.H. ${ }^{1,2}$

${ }^{1}$ Division of Rheumatology, Department of Internal Medicine, University of Nebraska Medical Center, Omaha, NE, USA

${ }^{2}$ Veterans Affairs Nebraska-Western lowa Health Care System

\section{Abstract}

Purpose of Review: Therapies for rheumatoid arthritis (RA) continue to expand rapidly. The purpose of this review is to discuss novel treatment options, including biosimilars, that are available, as well as to highlight promising agents in development. The purpose is also to discuss new emerging safety signals associated with these drugs and to discuss strategies in tapering therapy.

Recent Findings: There are several novel RA therapies. These include the interleukin 6 receptor blocker sarilumab, which was approved in 2017. In aggregate, the sarilumab studies show that it is effective in RA, including patients with incomplete responses to methotrexate and anti-tumor necrosis factor inhibitor, showing superior efficacy when used in higher dose (200 mg every two weeks) to standard-dose adalilumab. The two biosimilar drugs currently approved are CT-P13 and SB2, which are based on the reference product infliximab. Other drugs that are currently being studied include the interleukin- 6 cytokine blocker sarikumab, the small targeted molecule filgotinib, and many new biosimilars. Baracitinib failed to achieve approval by the FDA primarily over perceived safety concerns. Although this review summarizes trials examining biologic tapering, additional data is needed to guide clinicians in regards to treatment de-escalation in RA.

Summary: With the greatly expanded armamentarium of RA treatment options available, it is important for clinicians to understand the data regarding drug efficacy and safety. With remission increasingly attainable, effective drug tapering strategies are needed. While tapering trials do exist, more studies will be needed to help guide clinical practice.

\section{Keywords}

rheumatoid arthritis; treatment; biosimilar; sarilumab; tapering

\begin{abstract}
Rheumatoid arthritis (RA) is a chronic, progressive disease that, left untreated, leads to progressive joint destruction and disability. While there are many RA treatment options available, many agents are at best only partially effective or induce remission in only a minority of patients. Therefore, there remains an unmet need for treatments that provide excellent response and are cost-effective. The goal of this review is to identify novel
\end{abstract}

Corresponding Author: Tina Mahajan, M.D., 983025 Nebraska Medical Center, Omaha, NE, USA 68198-3025; Phone (402) 559-8168; Fax (402) 559-6788; tina.mahajan@unmc.edu.

Financial Support and Sponsorship: None 
therapies including both biologic and targeted synthetic disease modifying anti-rheumatic drugs (DMARDs), emerging safety issues with available agents, and data addressing the possibility of tapering therapies once remission is achieved.

\section{Novel Treatments}

\section{Interleukin (IL)-6 Inhibition}

Approved by the U.S. Food \& Drug Administration (FDA) in 2017, sarilumab is the newest biologic for the treatment of RA. A human monoclonal antibody directed against the alpha subunit of the IL-6 receptor complex, it has a unique structure and a higher affinity for the receptor compared to tocilizumab, the first IL-6 inhibitor to be approved in RA [1]. In addition to its association with chronic inflammation, IL-6 exhibits multiple immune regulatory effects [2]. IL-6, for instance, activates the Janus kinase (JAK) signaling inflammatory pathway by binding to the IL-6 receptor and gp130, a transmembrane protein. The IL-6 receptor has two isoforms, including the soluble and membrane form. While the soluble and membrane-bound receptors demonstrate similar affinity for IL-6, the soluble IL-6 receptor produces a wider range of biologic effects due to its broader distribution [3]. In turn, IL-6 blockade potently reduces the production of acute phase proteins, acts as an antipyretic [4], and decreases osteoclast formation and reduces bone erosion, the latter a characteristic feature of RA [5].

Sarilumab is indicated for the treatment of moderate-to-severe active RA with inadequate response or intolerance to methotrexate and can be used with or without concomitant methotrexate. The recommended dose is $150 \mathrm{mg}$ to $200 \mathrm{mg}$ subcutaneously every 2 weeks. In the wake of promising phase II findings [6], the efficacy of sarilumab was demonstrated in separate phase III studies. In a one-year study of RA patients with moderate-to-severe RA and inadequate responses to methotrexate, the addition of sarilumab $(150 \mathrm{mg}$ or $200 \mathrm{mg}$ every 2 weeks) to weekly methotrexate led to greater American College of Rheumatology (ACR)-20 treatment responses (58-66\%) vs. placebo (33\%, p<0.0001). Similar advantages of sarilumab over placebo were observed for the co-primary endpoints of radiographic progression and physical function [7]. In a separate 24-week study enrolling TNF-inhibitor (TNFi) incomplete responders receiving background conventional DMARD therapy, sarilumab administration resulted in similar benefit over placebo [8]. Finally, in a randomized double-blind head-to-head comparison of sarilumab (200 mg every 2 weeks) with adalimumab (40 mg every two weeks) monotherapy, sarilumab was statistically superior in terms of the change in 28 -joint disease activity score at 24 weeks (mean -3.28 vs. $-2.20, \mathrm{p}<0.0001)[9]$.

The tolerability of sarilumab was assessed in all of the above investigations, displaying a safety profile was relatively consistent across studies. The most common serious adverse effects reported included neutropenia, serious infections, hypersensitivity, and gastrointestinal perforations [10]. Neutropenia was seen in a significant percentage of patients, with varying degrees of severity, although no connection between neutropenia and infection risk could be established. There were significant liver function test (LFT) abnormalities (>3x upper limit of normal) in 3 to $8 \%$ of patients with a frequency of lipid abnormalities that approach that observed with tocilizumab [1]. Of note, in the head-to-head 
comparison, neutropenia and injection site reactions were more common with sarilumab than with adalimumab while headache was more common with the latter [9]. In aggregate, these studies show that sarilumab is effective in RA (including patients with incomplete responses to methotrexate and TNFi), showing superior efficacy when used in higher dose (200 mg every two weeks) to standard-dose adalimumab (a TNFi) with similar tolerability.

\section{Biosimilars}

Biosimilars represent an important new class of drugs in the rheumatologic armamentarium. Due to the complex molecular structure of biologics, generic versions of these drugs are not possible. Defined as a product that "has no clinically meaningful differences from an existing FDA-approved reference product" [11], regulatory agencies require that biosimilar agents pass stringent pharmacokinetic and pharmacodynamic testing, as well as immunogenicity assessments.

There are two biosimilar products based on the monoclonal antibody infliximab that are now approved for RA treatment in the U.S. The first to be approved was CT-P13 (Inflectra ${ }^{\circledR}$ ) in 2016. Approval was based in part on results from two 52-week, randomized double-blind, multinational, parallel group studies in which CT-P13 was compared to reference product (RP). Primary endpoints included efficacy defined by ACR20, ACR 50, and ACR70 responses, immunogenicity defined by anti-drug antibodies (ADAs), and safety defined as treatment emergent adverse events (TEAEs) [12, 13]. Recently, a 102 week, open-label extension study was completed to evaluate the safety and efficacy of switching to CT-P13 in patients already on the RP and to evaluate the longer term safety and efficacy of CT-P13 in patients who continue the agent for over two years [14]. Across these studies, there were no significant differences in efficacy, immunogenicity, or safety in patients taking (or switched to) CT-P13. In addition, the latter study showed that CT-P13 demonstrated persistent efficacy and tolerability over time, throughout the 102-weeks of observation [14].

SB2 (Renflexis ${ }^{\circledR}$ ) is the most recent infliximab biosimilar to be approved in the U.S. Approval in 2017 was based on two randomized double-bind, multinational, parallel group studies comparing SB2 to RP. Compared to the RP (infliximab), SB2 demonstrated a similar a safety profile as well as efficacy over 24 to 54 weeks of follow-up, both in terms of treatment response (ACR20) as well as retarding radiographic disease progression [15]. The most recent study of SB2 was an extension of the 54 week study, in which subjects receiving infliximab were re-randomized to either switch to SB2 or to continue on infliximab for up to 70 weeks [16]. The efficacy, safety, and immunogenicity profiles were similar between all of the groups as assessed at week 78. Additionally, there were no treatment related immunogenicity issues arising in subjects switching from infliximab to SB2.

\section{Emerging Therapies:}

\section{IL-6:}

In contrast to available IL-6 inhibitors, sirukumab is a monoclonal antibody that selectively binds to the cytokine, rather than its receptor. In a phase III multi-national, randomized double-blind study, sirukumab (50 mg every 4 weeks and $100 \mathrm{mg}$ every 2 weeks) was 
compared to placebo in RA patients who had failed conventional DMARDs [17]. Both coprimary endpoints of ACR20 response at 16 weeks and radiographic progression at 52 weeks were met, with similar efficacy observed between the high and low-dose sirukumab groups. A similar phase III study examined the use of sirukumab in RA patients failing prior anti-TNF therapy [18]. This trial met its primary outcome measure of ACR20 response at 16 weeks, again demonstrating similar efficacy across active treatment groups (ACR20 of 45\% with high dose and $40 \%$ with low dose) vs. placebo (24\%; $<<0.0001)$. Safety signals in these trials were similar to that of other IL-6 inhibitor drugs with the most common adverse events including LFT abnormalities, upper respiratory tract infections, and minor injection site reactions.

\section{Biosimilars:}

There are several biosimilars in various stages of development. Table 1 outlines biosimilars approved in the U.S. and those that are currently under evaluation by regulatory agencies.

\section{Targeted synthetic DMARDs:}

Bioavailable with oral administration, the targeted synthetic DMARDs that are currently available (tofacitinib) or in development target kinases involved in cell signaling. JAKs are intra-cellular cytoplasmic tyrosine kinases which signal cytokine signaling from membrane receptors to the cell nucleus. Four different types of JAKs are known: JAK1, JAK2, JAK3, and Tyk2. JAK1 and JAK3 transduce pro-inflammatory cytokine signaling, while JAK2 signals for a wider array of cytokines and is downstream of a number of growth factors involved in hematopoiesis [19]. Tofacitinib is a pan-JAK inhibitor, and the only drug in this class currently approved for use in the U.S. [20]. Baracitinib, another pan-JAK inhibitor, failed to gain approval in April of 2017, with the FDA citing the need for further dosing and safety data [21]. The major phase III study of baracitinib involved 527 patients with refractory RA, defined as those failing one or more previous TNFi, other biologic, or both [22]. More patients receiving baracitinib (4 $\mathrm{mg}$ daily) achieved the primary endpoint of ACR20 response at 12 weeks than placebo ( $55 \%$ vs. $27 \%$; p < 0.001$)$. Although rates of serious adverse events or those leading to study discontinuation were similar across treatment assignments, more patients treated with baracitinib $2 \mathrm{mg}$ or $4 \mathrm{mg}$ daily ( $71 \%$ to $77 \%$ ) experienced an adverse event than with placebo (64\%) after 24 weeks. Adverse events occurring more commonly with baracitinib included infections ( $44 \%$ and $40 \%$ vs. $31 \%$ ), decreased neutrophil counts, and slight increases in low-density lipoproteins that were accompanied by increases in high-density lipoprotein concentration. In a more recent openlabel extension study with up to 128 weeks of treatment exposure, the safety and tolerability profile of baracitinib (4 $\mathrm{mg}$ and $8 \mathrm{mg}$ doses) remained consistent with earlier observations while efficacy was maintained throughout the open-label period [23]. One particular safety concern cited by the FDA was the possible increased risk of thromboembolic events (deep venous thrombosis $[\mathrm{DVT}]$ and pulmonary embolus [PE]) related to baracitinib use. One recent study reviewed data from the FDA Adverse Event Reporting System (FAERS) to screen for thromboembolic events related to tofacitinib and ruxolitinib, the latter a JAK inhibitor used in certain myeloproliferative disorders. Although there was no evidence for elevated reporting of either DVT or PE for the individual agents, there were trends in the 
data suggesting that pulmonary embolism could represent an emerging class-wide adverse effect (Verden, Drug Safety, Dec 2017).

Filgotinib (GLPG0634/GS-6034) is a potent and selective inhibitor of JAK1 currently under development [24]. Pharmacokinetic and pharmacodynamic studies of filgotinib and its active metabolite suggest that both structures contribute to its pharmacodynamic properties, rendering a relatively long treatment half-life [25]. Filgotinib was initially found to be efficacious in two 4-week randomized trials conducted for proof-of-concept and dose finding purposes [24]. In separate phase II studies, filgotinib (100 or $200 \mathrm{mg}$, dosed once or twice daily) were significantly more efficacious than placebo in achieving ACR20, -50 , and -70 responses while demonstrating similar adverse event rates [26, 27]. Importantly, the trial patients receiving filgotinib showed slight increases in hemoglobin during observation, in contrast to patients on pan-JAK inhibitors who can develop anemia, likely mediated by JAK2 inhibition [19]. Table 2 summarizes the current filgotinib trials.

\section{Herpes Zoster as an Emerging Safety Issue}

Herpes zoster (HZ) incidence has been increasingly identified as an adverse event in RA treatment trials, with data suggesting that its risk may be disproportionately higher with tofacitinib use. An initial study identifying all cases from phase II, -III, and long-term extension RA trials of tofacitinib showed that the $\mathrm{HZ}$ incidence rate (IR) was 4.4 per 100 person years (95\% CI 3.8 to 4.9) [28]. Importantly, complicated HZ cases were rare in these studies and there were no cases of visceral dissemination or death from these databases. More recently, a study was done to identify other risk factors for $\mathrm{HZ}$ complicating the course of tofacitinib treatment in RA [29]. Using similar datasets as described above and multivariable Cox regression, the authors identified several other potential independent risk factors including: older age (Hazard Ratio [HR] 1.41; 95\% CI 1.31-1.52 per 10 years); glucocorticoid use (HR 1.49; 95\% CI 1.22-1.82 for $>0 \mathrm{mg}$ to $5 \mathrm{mg}$ /day of prednisone equivalent or HR 1.41; 95\% CI 1.12-1.77 vs. 0 mg); region of enrollment (with Asians having the highest risk); and former or never smoking status (HR 1.32; 95\% CI 1.04-1.69 vs. current smoker).

With known risk for $\mathrm{HZ}$, vaccination of patients is an important consideration. A recent phase II, randomized controlled trial compared the safety and immunogenicity of the live zoster vaccine in RA patients (all receiving background methotrexate) treated with tofacitinib (5 mg twice daily) vs. placebo administered 2-3 weeks post-vaccination[30]. Importantly, this study showed similar vaccine mediated immune responses in those receiving tofacitinib vs. placebo. Moreover, the vaccine appeared to be well tolerated in all but one patient who lacked preexisting viral immunity and who developed cutaneous vaccine dissemination 2 days after initiating tofacitinib (16 days after being vaccinated). These data suggest that the live zoster vaccine may be an effective tool in mitigating this adverse effect and may be administered safely in a majority of patients within 2-3 weeks of initiating tofacitinib. In September of 2017, the FDA approved a non-live shingles vaccine consisting of a recombinant VZV antigen and an immune adjuvant. A recent study was done to evaluate the immunogenicity and safety of the inactivated vaccine in patients with autoimmune disease on immunosuppressive agents (both biologic and non-biologic). The 
vaccine was found to elicit robust humoral and cell-mediated responses and was relatively well tolerated with the most common adverse effect being injection site reactions. Two serious adverse events in the vaccine group were determined by investigators to be related to vaccine including one case of keratitis and another of amnesia (Eberhardsen, Clin Infect Dis).

\section{Tapering Therapies:}

With the advent of multiple new therapies for RA, disease remission is now a more achievable goal. In patients who achieve remission by any definition, the concept of tapering therapy is an important consideration. In fact, recent treatment guidelines suggest tapering either DMARDs or biologic therapies in patients with established RA who are in remission. The quality of evidence, however, endorsing this practice is low [31]. While several deescalation studies have been undertaken, these are difficult to compare due to clinical heterogeneity of the populations studied as well as differences in methodologies.

A systematic review of de-escalation studies was done in 2014 [32]. This review aimed to assess the literature supporting "biologic down-titration". The authors identified 10 studies in the report, only 3 of which were randomized controlled trials (RCTs). Based on the limited data available at the time, the authors concluded that it was difficult to determine which patients needed to remain on therapy and which patients could be safely undergo biologic tapering without flaring and that more studies were needed. Since then, several additional RCTs have been completed (Table 3 ).

Further studies have aimed to help determine predictors of flare with treatment tapering. The tREACH and RETRO studies examined rates of flare with tapering of either conventional synthetic DMARDs or biologics $[33,34]$. Of note, the RETRO study was published as a one-year interim analysis and reported that disease relapses were associated with the presence of anti-citrullinated protein antibody (ACPA). In a follow-up to this, 94 baseline serum samples from RETRO subjects were tested for immune responses to 10 different modified (citrullinated, homocitrullinated and acetylated) peptides. Among these patients undergoing standardized DMARD/biologic tapering or discontinuation, the more antimodified protein antibodies a patient had, the more likely their disease would relapse [35]. The proportion flaring ranged from $18 \%$ in those with none or one autoantibody positive to $55 \%$ in those with $>5$ positive autoantibodies. Both the RETRO study and tREACH trials showed that female sex was also a predictor of flare. Finally, one recent 18-month noninferiority study examined the utility of a baseline multi-disease biomarker disease activity (MBDA) score to predict flare in RA patients (all in sustained remission at baseline) whose medication was tapered or stopped [36]. The results showed that the baseline MBDA score, although associated with the occurrence of flare in those receiving usual care, was not a good predictor of disease relapse in those tapering therapies.

Another important aspect of tapering therapy is whether patients can regain remission if therapy is resumed after being stopped. The tREACH trial showed that approximately $65 \%$ of patients regained remission within six months of treatment intensification [33]. This is consistent with the systemic review of studies done before 2014 [32]. Of note, the tREACH 
population was an early RA group and it is unclear whether those with more established RA would respond similarly.

Many trials suggest that tapering the dose or frequency of the biologic drug, rather than completely stopping it, may be a more effective alternative in maintaining RA treatment response. The PRESERVE and PRIZE trials showed that patients on a reduced dose of etanercept ( $25 \mathrm{mg}$ s.c. weekly) maintained remission as well as those on full dose etanercept (50 mg s.c. weekly), but those whose etanercept was stopped were far less likely to maintain remission $[37,38]$. The OPTTIRA trial was an open-label trial that also looked at this concept [39], comparing tapering of TNFi (adalimumab or etanercept) by either $33 \%$ or $66 \%$ percent to stable-dosed treatment. Compared to those receiving stable, standard TNFi dosing, $66 \%$ tapering was associated with a reduced time-to-flare in survival analysis, an effect that was not observed with $33 \%$ tapering.

\title{
Conclusions:
}

The RA treatment armamentarium has expanded substantially over the last twenty years. In this review, we have summarized the latest biologics/biosimilars and targeted small molecule drugs on the market, other promising agents in development, as well as emerging safety signals associated with newer treatment options. With these many treatment options, remission has become increasingly obtainable and the question of tapering strategies has become highly relevant in the day-to-day management of RA patients. Future trials will continue to help guide clinicians in best practices in the treatment of RA.

\section{Acknowledgements:}

\author{
None
}

Conflicts of Interest: Dr. Mikuls receives research funding from the National Institutes of Health, Veterans Affairs, the Rheumatology Research Foundation, and Bristol Myers Squibb. Dr. Mikuls also serves as a paid consultant for Pfizer.

\section{References:}

- of special interest

- of outstanding interest

1. Aly AM, Furst DE. Update of sarilumb to treat rheumatoid arthritis based on randomized clinical trials: a systematic review. Expert Rev Clin Immunol 2017; 13:741-752. [PubMed: 28689441]

2. Gabay C Interleukin-6 and chronic inflammation. Arthritis research \& therapy 2006; 8 Suppl 2:S3.

3. Calabrese LH, Rose-John S. IL-6 biology: implications for clinical targeting in rheumatic disease. Nat Rev Rheumatol 2014; 10:720-727. [PubMed: 25136784]

4. Tanaka T, Kishimoto T. The biology and medical implications of interleukin-6. Cancer immunology research 2014; 2:288-294. [PubMed: 24764575]

5. Axmann R, Bohm C, Kronke G, et al. Inhibition of interleukin-6 receptor directly blocks osteoclast formation in vitro and in vivo. Arthritis and rheumatism 2009; 60:2747-2756. [PubMed: 19714627]

6. Huizinga TW, Fleischmann RM, Jasson M, et al. Sarilumab, a fully human monoclonal antibody against IL-6Ralpha in patients with rheumatoid arthritis and an inadequate response to methotrexate: efficacy and safety results from the randomised SARIL-RA-MOBILITY Part A trial. 
Ann Rheum Dis 2014; 73:1626-1634. [PubMed: 24297381] *This trial is noteworthy because it examined a large range of doses in MTX-IR patients.

7. Genovese MC, Fleischmann R, Kivitz AJ, et al. Sarilumab Plus Methotrexate in Patients With Active Rheumatoid Arthritis and Inadequate Response to Methotrexate: Results of a Phase III Study. Arthritis Rheumatol 2015; 67:1424-1437. [PubMed: 25733246]

8. Fleischmann R, van Adelsberg J, Lin Y, et al. Sarilumab and Nonbiologic Disease-Modifying Antirheumatic Drugs in Patients With Active Rheumatoid Arthritis and Inadequate Response or Intolerance to Tumor Necrosis Factor Inhibitors. Arthritis Rheumatol 2017; 69:277-290. [PubMed: 27860410]

9. Burmester GR, Lin Y, Patel R, et al. Efficacy and safety of sarilumab monotherapy versus adalimumab monotherapy for the treatment of patients with active rheumatoid arthritis (MONARCH): a randomised, double-blind, parallel-group phase III trial. Ann Rheum Dis 2017; 76:840-847. [PubMed: 27856432] **This trial is the only sarilumab monotherapy trial and overall favored sarilumab monotherapy versus adalimumab monotherapy in terms of HAQ-DI, TJC, and SJC.

10. HIGHLIGHTS OF PRESCRIBING INFORMATION [KEVZARA]. Bridgewater, NJ: Sanofi and Regeneron Pharmaceuticals, Inc. Published May 2017. Accessed December 15, 2017 http:// products.sanofi.us/kevzara/kevzara.pdf

11. Biosimilar and Interchangeable Products. Silver Springs, MD: Published 10/23/2017 Accessed 12/15/17 https://www.fda.gov/Drugs/DevelopmentApprovalProcess/ HowDrugsareDevelopedandApproved/ApprovalApplications/TherapeuticBiologicApplications/ Biosimilars/ucm580419.htm\#biosimilar

12. Yoo DH, Hrycaj P, Miranda P, et al. A randomised, double-blind, parallel-group study to demonstrate equivalence in efficacy and safety of CT-P13 compared with innovator infliximab when coadministered with methotrexate in patients with active rheumatoid arthritis: the PLANETRA study. Ann Rheum Dis 2013; 72:1613-1620. [PubMed: 23687260]

13. Yoo DH, Racewicz A, Brzezicki J, et al. A phase III randomized study to evaluate the efficacy and safety of CT-P13 compared with reference infliximab in patients with active rheumatoid arthritis: 54-week results from the PLANETRA study. Arthritis research \& therapy 2016; 18:82. [PubMed: 27038608]

14. Yoo DH, Prodanovic N, Jaworski J, et al. Efficacy and safety of CT-P13 (biosimilar infliximab) in patients with rheumatoid arthritis: comparison between switching from reference infliximab to CTP13 and continuing CT-P13 in the PLANETRA extension study. Ann Rheum Dis 2017; 76:355363. [PubMed: 27130908] *This trial was a 102-week open label extension study in which patients were either switched to CT-P13 from infliximab or were continued on CT-P13. It showed no change in efficacy, safety, and immunogenicity in patients who were switched to, or those who continued CT-P13.

15. Choe JY, Prodanovic N, Niebrzydowski J, et al. A randomised, double-blind, phase III study comparing SB2, an infliximab biosimilar, to the infliximab reference product Remicade in patients with moderate to severe rheumatoid arthritis despite methotrexate therapy. Ann Rheum Dis 2017; 76:58-64. [PubMed: 26318384]

16. Smolen JS, Choe JY, Prodanovic N, et al. Safety, immunogenicity and efficacy after switching from reference infliximab to biosimilar SB2 compared with continuing reference infliximab and SB2 in patients with rheumatoid arthritis: results of a randomised, double-blind, phase III transition study. Ann Rheum Dis 2017.*This trial was a 70-week open label extension study in which patients were either switched to SB2 from infliximab or were continued on SB2. It showed no change in efficacy, safety, and immunogenicity in patients who were switched to, or continued on, SB2.

17. Takeuchi T, Thorne C, Karpouzas G, et al. Sirukumab for rheumatoid arthritis: the phase III SIRROUND-D study. Ann Rheum Dis 2017; 76:2001-2008. [PubMed: 28855173]

18. Aletaha D, Bingham CO,, 3rd, Tanaka Y, et al. Efficacy and safety of sirukumab in patients with active rheumatoid arthritis refractory to anti-TNF therapy (SIRROUND-T): a randomised, doubleblind, placebo-controlled, parallel-group, multinational, phase 3 study Lancet (London, England) 2017; 389:1206-1217. [PubMed: 28215362] 
19. O'Shea JJ, Schwartz DM, Villarino AV, et al. The JAK-STAT pathway: impact on human disease and therapeutic intervention. Annual review of medicine 2015; 66:311-328.

20. Kaur K, Kalra S, Kaushal S. Systematic review of tofacitinib: a new drug for the management of rheumatoid arthritis. Clinical therapeutics 2014; 36:1074-1086. [PubMed: 25047498]

21. FDA issues concerns about optimal baricitinib doses for the treatment of moderate-to-severe rheumatoid arthritis and delays drug approval. Rheumatology (Oxford) 2017; 56:e22. [PubMed: 28854620]

22. Genovese MC, Kremer J, Zamani O, et al. Baricitinib in Patients with Refractory Rheumatoid Arthritis. The New England journal of medicine 2016; 374:1243-1252. [PubMed: 27028914]

23. Keystone EC, Genovese MC, Schlichting DE, et al. Safety and Efficacy of Baricitinib Through 128 Weeks in an Open-label, Longterm Extension Study in Patients with Rheumatoid Arthritis. The Journal of rheumatology 2017.**This trial is noteworthy because it provides longer-term data on the safety and efficacy of baracitinib through 128-week open label extension period. No new safety signals were seen and the drug remained effective throughout.

24. Vanhoutte F, Mazur M, Voloshyn O, et al. Efficacy, Safety, Pharmacokinetics, and Pharmacodynamics of Filgotinib, a Selective JAK-1 Inhibitor, After Short-Term Treatment of Rheumatoid Arthritis: Results of Two Randomized Phase IIa Trials. Arthritis Rheumatol 2017; 69:1949-1959. [PubMed: 28622463]

25. Namour F, Diderichsen PM, Cox E, et al. Pharmacokinetics and Pharmacokinetic/ Pharmacodynamic Modeling of Filgotinib (GLPG0634), a Selective JAK1 Inhibitor, in Support of Phase IIB Dose Selection. Clinical pharmacokinetics 2015; 54:859-874. [PubMed: 25681059]

26. Westhovens R, Taylor PC, Alten R, et al. Filgotinib (GLPG0634/GS-6034), an oral JAK1 selective inhibitor, is effective in combination with methotrexate (MTX) in patients with active rheumatoid arthritis and insufficient response to MTX: results from a randomised, dose-finding study (DARWIN 1). Ann Rheum Dis 2017; 76:998-1008. [PubMed: 27993829]

27. Kavanaugh A, Kremer J, Ponce L, et al. Filgotinib (GLPG0634/GS-6034), an oral selective JAK1 inhibitor, is effective as monotherapy in patients with active rheumatoid arthritis: results from a randomised, dose-finding study (DARWIN 2). Ann Rheum Dis 2017; 76:1009-1019. [PubMed: 27993828]

28. Winthrop KL, Yamanaka H, Valdez H, et al. Herpes zoster and tofacitinib therapy in patients with rheumatoid arthritis. Arthritis Rheumatol 2014; 66:2675-2684. [PubMed: 24943354] **This paper is noteworthy because it identifies alll cases of herpes zoster from phase -II -III, and open label extension trials to determine a $\mathrm{HZ}$ incidence rate (IR) as 4.4 per 100 person years (95\% CI 3.8 to 4.9).

29. Winthrop KL, Curtis JR, Lindsey S, et al. Herpes Zoster and Tofacitinib: Clinical Outcomes and the Risk of Concomitant Therapy. Arthritis Rheumatol 2017; 69:1960-1968. [PubMed: 28845604] *This paper is noteworthy because it identified additional risk factors for development of zoster in RA patients on tofacitinib.

30. Winthrop KL, Wouters AG, Choy EH, et al. The Safety and Immunogenicity of Live Zoster Vaccination in Patients With Rheumatoid Arthritis Before Starting Tofacitinib: A Randomized Phase II Trial. Arthritis Rheumatol 2017; 69:1969-1977. [PubMed: 28845577] *This trial is noteworthy because it sought to determine whether live zoster vaccine was effective and safe if given within 2-3 weeks of initiation of tofacitinib.

31. Singh JA, Saag KG, Bridges SL, Jr., et al. 2015 American College of Rheumatology Guideline for the Treatment of Rheumatoid Arthritis. Arthritis Rheumatol 2016; 68:1-26.

32. van Herwaarden N, den Broeder AA, Jacobs W, et al. Down-titration and discontinuation strategies of tumor necrosis factor-blocking agents for rheumatoid arthritis in patients with low disease activity. The Cochrane database of systematic reviews 2014:Cd010455. [PubMed: 25264908]

33. Kuijper TM, Luime JJ, de Jong PH, et al. Tapering conventional synthetic DMARDs in patients with early arthritis in sustained remission: 2-year follow-up of the tREACH trial. Ann Rheum Dis 2016; 75:2119-2123. [PubMed: 27283332] **This trial is noteworthy because it not only assessing tapering strategies but also looks at the rate of remission after therapy is reinitiated after a flare. 
34. Haschka J, Englbrecht M, Hueber AJ, et al. Relapse rates in patients with rheumatoid arthritis in stable remission tapering or stopping antirheumatic therapy: interim results from the prospective randomised controlled RETRO study. Ann Rheum Dis 2016; 75:45-51. [PubMed: 25660991]

35. Figueiredo CP, Bang H, Cobra JF, et al. Antimodified protein antibody response pattern influences the risk for disease relapse in patients with rheumatoid arthritis tapering disease modifying antirheumatic drugs. Ann Rheum Dis 2017; 76:399-407. [PubMed: 27323772]

36. Bouman CAM, van der Maas A, van Herwaarden N, et al. A multi-biomarker score measuring disease activity in rheumatoid arthritis patients tapering adalimumab or etanercept: predictive value for clinical and radiographic outcomes. Rheumatology (Oxford) 2017; 56:973-980. [PubMed: 28339738]

37. Smolen JS, Nash P, Durez P, et al. Maintenance, reduction, or withdrawal of etanercept after treatment with etanercept and methotrexate in patients with moderate rheumatoid arthritis (PRESERVE): a randomised controlled trial Lancet (London, England) 2013; 381:918-929. [PubMed: 23332236] *This trial is noteworthy because it showed that both standard and reduced doses of etanercept were more effective at maintaining remission compared to methotrexate alone.

38. Emery P, Hammoudeh M, FitzGerald O, et al. Sustained remission with etanercept tapering in early rheumatoid arthritis. The New England journal of medicine 2014; 371:1781-1792. [PubMed: 25372086]

39. Ibrahim F, Lorente-Canovas B, Dore CJ, et al. Optimizing treatment with tumour necrosis factor inhibitors in rheumatoid arthritis-a proof of principle and exploratory trial: is dose tapering practical in good responders? Rheumatology (Oxford) 2017; 56:2004-2014. [PubMed: 28968858] *This is an open label trial looking at the concept of reduced dose of a biologic (adalilumab or etanercept). It showed that reduction by $66 \%$ was associated with a reduced time-to-flare in survival analysis, but reduction by $33 \%$ did not have this same association.

40. Emery P, Vencovsky J, Sylwestrzak A, et al. Long-term efficacy and safety in patients with rheumatoid arthritis continuing on SB4 or switching from reference etanercept to SB4. Ann Rheum Dis 2017.

41. Cohen S, Genovese MC, Choy E, et al. Efficacy and safety of the biosimilar ABP 501 compared with adalimumab in patients with moderate to severe rheumatoid arthritis: a randomised, doubleblind, phase III equivalence study. Ann Rheum Dis 2017; 76:1679-1687. [PubMed: 28584187]

42. Smolen JS, Cohen SB, Tony HP, et al. A randomised, double-blind trial to demonstrate bioequivalence of GP2013 and reference rituximab combined with methotrexate in patients with active rheumatoid arthritis. Ann Rheum Dis 2017; 76:1598-1602. [PubMed: 28637670]

43. Smolen JS, Emery P, Fleischmann R, et al. Adjustment of therapy in rheumatoid arthritis on the basis of achievement of stable low disease activity with adalimumab plus methotrexate or methotrexate alone: the randomised controlled OPTIMA trial Lancet (London, England) 2014; 383:321-332. [PubMed: 24168956]

44. Glinatsi D, Heiberg MS, Rudin A, et al. Head-to-head comparison of aggressive conventional therapy and three biological treatments and comparison of two de-escalation strategies in patients who respond to treatment: study protocol for a multicenter, randomized, open-label, blindedassessor, phase 4 study. Trials 2017; 18:161. [PubMed: 28376912] *This trial is currently ongoing and will not only compare initial RA treatments but then will subsequently compare two tapering strategies in those who respond to treatment.

45. Verden A, Dimbil M, Kyle R, et al. Analysis of Spontaneous Postmarket Case Reports Submitted to the FDA Regarding Thromboembolic Adverse Events and JAK Inhibitors. Drug safety 2017. 


\section{Key points:}

- $\quad$ Recent advances in RA treatment include the availability of biosimilars as well as novel agents inhibiting IL-6 and JAK.

- $\quad$ Recent findings have identified risk factors the development of Herpes Zoster (HZ) complicating tofacitinib in RA and these include older age, concomitant glucocorticoid use, geographic region of residence, and smoking status.

- $\quad$ Although several promising trials suggest that biologic therapies can be successfully tapered in some patients with RA, further study is needed to identify optimal candidates and approaches of treatment de-escalation. 
Table 1:

Current Biosimilars on the Market and Pending Approval in US

\begin{tabular}{|l|l|l|l|}
\hline \multicolumn{1}{|c|}{ Drug (Trade name) } & Reference Product & \multicolumn{1}{c|}{ Approval Status } & \multicolumn{1}{c|}{ Trials } \\
\hline CT-P13 (Inflectra@) & Infliximab & Approved in US in 2016 & PLANETRA, PLANETRA extension[13, 14]. \\
\hline SB2 (Renflexis@) & Infliximab & Approved in the US in 2017 & $\begin{array}{l}\text { Choe. Ann Rheum Dis 2017 [15]. } \\
\text { Smolen. Ann Rheum Dis 2017[16]. }\end{array}$ \\
\hline SB4 (Benepali, Brenzys@) & Etanercept & $\begin{array}{l}\text { Approved in Europe, Current US } \\
\text { clinical trial }\end{array}$ & $\begin{array}{l}\text { http://ClinicalTrials.gov:NCT01895309 } \\
\text { Ann Rheum Dis 2017 [40]. }\end{array}$ \\
\hline ABP501 & Adalilumab & Current US clinical trials & $\begin{array}{l}\text { http://ClinicalTrials.gov:NCT01970475 } \\
\text { Ann Rheum Dis. 2017 [41]. }\end{array}$ \\
\hline GP2013 & Rituximab & Current US clinical trials & $\begin{array}{l}\text { http://ClinicalTrials.gov:NCT01274182 } \\
\text { Ann Rheum Dis. 2017 [42]. }\end{array}$ \\
\hline
\end{tabular}


Table 2:

Summary of Filgotinib (selective JAK-1 inhibitor) Trials

\begin{tabular}{|l|l|l|l|l|l|}
\hline Trial & Type & Length & Number & Efficacy \\
\hline $\begin{array}{l}\text { DARWIN 1 } \\
\text { Annals Rheum } \\
\text { Disease, 2017 [26]. }\end{array}$ & $\begin{array}{l}\text { Phase IIb, multicenter, } \\
\text { multinational, } \\
\text { including US }\end{array}$ & 24 weeks & $\begin{array}{l}\text { 594 received placebo } \\
\text { vs drug at various } \\
\text { doses and } \\
\text { methotrexate }\end{array}$ & $\begin{array}{l}\text { Drug met ACR endpoints } \\
\text { at 12 weeks for doses 100 } \\
\text { mg and 200 mg, but not } \\
\text { for lower doses }\end{array}$ & $\begin{array}{l}\text { No significant } \\
\text { differences in adverse } \\
\text { and drug groups }\end{array}$ \\
\hline $\begin{array}{l}\text { DARWIN 2 } \\
\text { Annals Rheum } \\
\text { Disease, 2017 [27]. }\end{array}$ & $\begin{array}{l}\text { Phase IIb, multicenter, } \\
\text { multinational } \\
\text { including US }\end{array}$ & 24 weeks & $\begin{array}{l}\text { 283 received placebo } \\
\text { vs drug at various } \\
\text { doses, no } \\
\text { methotrexate }\end{array}$ & $\begin{array}{l}\text { Drug met ACR endpoints } \\
\text { starting at week 12 and } \\
\text { persisted week 24 }\end{array}$ & $\begin{array}{l}\text { No significant } \\
\text { difference in adverse } \\
\text { events between placebo } \\
\text { and drug group }\end{array}$ \\
\hline $\begin{array}{l}\text { Arthritis and } \\
\text { Rheumatology, 2017 } \\
\text { [24]. }\end{array}$ & $\begin{array}{l}\text { Phase IIa, proof of } \\
\text { concept study done in } \\
\text { Republic of Maldova }\end{array}$ & 4 weeks & $\begin{array}{l}36 \text { received placebo } \\
\text { vs drug at 100 or 200 } \\
\text { mg dose }\end{array}$ & $\begin{array}{l}\text { Drug met ACR endpoints } \\
\text { vs placebo }\end{array}$ & $\begin{array}{l}\text { No major safety } \\
\text { signals. Hemoglobin } \\
\text { went up, decrease in } \\
\text { neutrophils without } \\
\text { neutropenia }\end{array}$ \\
\hline $\begin{array}{l}\text { Arthritis and } \\
\text { Rheumatology, 2017 } \\
\text { [24]. }\end{array}$ & $\begin{array}{l}\text { Phase IIa, dose } \\
\text { ranging study in } \\
\text { Republic of Maldova, } \\
\text { Ukraine, Russia, and } \\
\text { Hungary }\end{array}$ & 4 weeks & $\begin{array}{l}91 \text { received placebo } \\
\text { various doses of drug }\end{array}$ & $\begin{array}{l}85 \% \text { of 300 mg dose } \\
\text { group had a ACR 20 } \\
\text { response but this was not } \\
\text { significantly better than } \\
\text { placebo }\end{array}$ & $\begin{array}{l}\text { No major safety } \\
\text { signals. Hemoglobin } \\
\text { went up, decrease in } \\
\text { neutrophils without } \\
\text { neutropenia. }\end{array}$ \\
\hline
\end{tabular}

Abbreviations: ACR - American College of Rheumatology 
Table 3:

Summary of Recent De-escalation Trials

\begin{tabular}{|c|c|c|}
\hline Trial & Methods & Results \\
\hline $\begin{array}{l}\text { PRESERVE: Lancet } 2013 \text { [37]. } \\
\text { To evaluate whether patients can } \\
\text { maintain low disease activity (LDA) } \\
\text { despite tapering or stopping of } \\
\text { etanercept (ETA) }\end{array}$ & $\begin{array}{l}\text { RCT in moderately active RA, } 3 \text { arms: } \\
\text { ETA 50+MTX, Enbrel } 25+\text { MTX, placebo } \\
+ \text { MTX }\end{array}$ & $\begin{array}{l}\text { Author conclusion: standard and reduced doses of } \\
\text { etanercept are more effective at maintaining remission } \\
\text { than MTX alone }\end{array}$ \\
\hline $\begin{array}{l}\text { PRIZE: NEJM } 2014 \text { [38]. } \\
\text { To evaluate whether patients with } \\
\text { early RA, after induction, can } \\
\text { maintain LDA without ETA }\end{array}$ & $\begin{array}{l}\text { RCT in early RA patients, } 3 \text { groups: ETA } \\
25+\text { MTX, MTX, and placebo }\end{array}$ & $\begin{array}{l}\text { Author conclusion: After early, aggressive treatment } \\
\text { of tapering of RA achieving LDA, tapering biologic is } \\
\text { appropriate, reduced dose of ETA is more effective at } \\
\text { maintaining remission than MTX alone }\end{array}$ \\
\hline $\begin{array}{l}\text { OPTIMA: Lancet } 2014 \text { [43]. } \\
\text { To assess different treatment } \\
\text { adjustment strategies in early RA } \\
\text { patients attaining (or not) LDA with } \\
\text { adalilumab (ADA) + MTX vs MTX } \\
\text { alone }\end{array}$ & $\begin{array}{l}\text { RCT in early RA patients, patients phase } 1 \\
\text { ( } 24 \text { wk) treated with either MTX or MTX } \\
\text { +ADA, then those who achieved LDA } \\
\text { were either continued on their regimen or } \\
\text { ADA removed for phase } 2 \text { (additional } 52 \\
\text { wk) }\end{array}$ & $\begin{array}{l}\text { Author conclusion: Patients who achieved LDA } \\
\text { initially on MTX+ADA who then withdrew ADA } \\
\text { mostly maintained good clinical responses }\end{array}$ \\
\hline $\begin{array}{l}\text { RETRO: Ann Rheum Dis } 2016 \text { [34]. } \\
\text { To assess different tapering strategies } \\
\text { in established RA patients. }\end{array}$ & $\begin{array}{l}\text { RCT in established RA, } 3 \text { arms: continue } \\
\text { all meds, tapering DMARD or biologic, } \\
\text { stopping all medications at } 6 \text { months after } \\
\text { tapering, endpoint was an Interim Analysis } \\
\text { of relapse at } 12 \text { months }\end{array}$ & $\begin{array}{l}\text { Author conclusion: There was a significant difference } \\
\text { in relapse rates between the groups that continued and } \\
\text { stopped the medications, but no difference between } \\
\text { the groups that were continued and those that were } \\
\text { tapered. }\end{array}$ \\
\hline $\begin{array}{l}\text { tREACH: Ann Rheum Dis } 2016 \text { [33]. } \\
\text { To compare different tapering } \\
\text { strategies and to determine whether } \\
\text { remission could be regained after } \\
\text { flare. }\end{array}$ & $\begin{array}{l}\text { RCT in early RA patients, patients in DAS } \\
\text { remission were tapered according to } \\
\text { protocol, outcomes were sustained } \\
\text { remission, rates of flare, and remission } \\
\text { after flare }\end{array}$ & $\begin{array}{l}\text { Author conclusion: There was a similar rate of flare } \\
\text { when tapering biological vs conventional DMARDs } \\
(37 \% \text { vs } 47 \%) \text {. After flare, } 65 \% \text { of flare patients } \\
\text { regained remission after increasing therapy. }\end{array}$ \\
\hline NORD-STAR: Trials 2017 [44]. & $\begin{array}{l}\text { Prospective RCT, arms: Immediate taper, } \\
\text { slow taper, stop meds }\end{array}$ & Trial ongoing currently \\
\hline
\end{tabular}

Abbreviations: LDA - Low disease activity; ETA - etanercept; MTX - methotrexate; ADA - adalimumab 